\title{
The economic burden of allergy in pediatric severe asthma
}

\author{
Gizem Pamuk ${ }^{1}$, Muriel Le Bourgeois ${ }^{1}$, Rola Abou Taam ${ }^{1}$, Jacques de Blic ${ }^{1}$, Christophe \\ Delacourt $^{1}$, and Guillaume LEZMI ${ }^{1}$ \\ ${ }^{1}$ Hôpital universitaire Necker-Enfants malades
}

October 5, 2020

\section{To the Editor:}

Severe asthma (SA) affects less than $5 \%$ of the pediatric asthma population but is considered to account for approximately half of total pediatric asthma healthcare costs. Allergic comorbidities, including food allergies (FA) and allergic rhinitis (AR), are frequent in children with SA (1). The presence of FA and AR increases asthma severity (1-6) and medication use (4-6). Treating AR improves asthma symptoms (3). However, the economic burden of allergy in children with SA has been poorly studied. We aimed to determine the economic contribution of allergy for the French national health insurance (NHI) for the treament of children with SA at the individual level.

Children with SA, defined as those requiring step 4 or 5 of treatment of the Global Initiative for Asthma (GINA), regularly followed in the Department of Pediatric Pulmonology of Necker Hospital were included as previously described (7). The diagnosis of SA, FA, and AR were made by a physician according to guidelines (8-10). A physician-guided questionnaire was completed with parents to assess individual expenditures related to asthma and allergic comorbidities in the previous six months. Parental claims were confirmed by analysis of the medical records. The methods are detailed elsewhere (7). First, we determinated the direct, indirect, and global costs of SA over a six-month period (7) and then assessed the allergy-related costs. The costs related to allergy included anti-allergic medications (oral antihistamines, steroid nasal sprays, antiallergic eye drops, adrenaline autoinjectors, and allergen immunotherapy), anti-IgE treatment, scheduled ambulatory or hospital outpatient visits to an allergist, pulmonologist, ophthalmologist, or dermatologist, skin tests, blood tests for allergy-specific IgE, and day care unit (DCU) admissions for oral food challenge (OFC) (7). Finally, we compared the economic burden of allergy between children with SA and those without (NSA) (7). Parents were informed and accepted to participate in the study. The local ethical committee confirmed that Institutional Review Board approval was not required.

Forty-eight children with SA and 26 with NSA were included. Their general characteristics are summarized in Table 1. The individual global cost of SA was $\backslash$ euro3,982 $(4,422)$ over the six-month study period (7). For children with allergic SA, the cost attributed to allergy was $\backslash$ euro2,803 (3,709), representing 48.1\% (35.2) of the direct SA costs and $45.8 \%$ (34.9) of the global SA costs. Overall, the number of allergic comorbidities for children with SA weakly correlated with global $(\mathrm{r}=0.33, \mathrm{p}=0.02)$ and direct SA costs $(\mathrm{r}=0.35, \mathrm{p}=0.01)$. The global and direct costs of SA were higher for children with allergic comorbidities than for those without ( $\backslash$ euro4,646 (4,635) vs. \euro1,107 (1,173), $\mathrm{p}=0.02$; respectively). However, these figures partially reflect the actual economic contribution of allergy in children with allergic SA. For those requiring omalizumab, the economic burden of allergy was $\backslash$ euro5,057 $(3,809)$ representing $74.1 \%(24.4)$ of direct SA costs and $71.6 \%$ (24.3) of global SA costs. In this group, omalizumab was the main driver of costs, representing $73.6 \%$ of direct SA costs and $71.5 \%$ of global SA costs. For children with allergic SA not requiring omalizumab, the economic burden of allergy was \euro174.50 (289.7), representing $17.8 \%$ (16.1) of direct SA costs and 15.8\% (15.9) of global SA costs. Regardless of omalizumab use, the economic burden of allergy was similar among children with allergic SA (\euro153.3 (159.4) vs \euro174.50 (289.7), p = 0.99). However, the burden of 
allergy expressed as a percentage of direct and global SA costs was lower for children with SA requiring omalizumab than those who did not (3\% (4.2) vs. $17.8 \%$ (16.1), p $<0.01$ and $2.9 \%$ (4.2) vs. $15.8 \%$ (15.9), $\mathrm{p}<0.01$, respectively).

Global, direct, and indirect costs did not differ between children with NSA, with or without allergic comorbidity (Table 3). For children with allergic NSA, the cost of allergy was \euro134.40 (213.90), representing $40.8 \%(33.3)$ of the asthma direct costs and $34.7 \%$ (32.2) of the asthma global costs. Thus, regardless of omalizumab use, the cost of allergy for children with allergic SA and that for those with allergic NSA was similar ( $\backslash$ euro163.1 (225.9) vs . \euro134.40 (213.9) ( $\mathrm{p}=0.19)$. However, the economic burden of allergy was greater for children with NSA than those with SA: $40.8 \%$ vs $9.8 \%$ of direct costs and $34.7 \%$ vs. $8.9 \%$ of global costs, respectively (both $\mathrm{p}<0.01$ ). Finally, the economic burden of allergy was similar between children with allergic SA not requiring omalizumab and those with allergic NSA ( \euro174.5 (289.7 vs. \euro134.4 (213.9), $\mathrm{p}=0.29)$.

This study shows that the costs attributed to allergy for children with SA are substantial and mostly driven by omalizumab, but are minor when omalizumab is not taken into account. The economic burden of allergy was similar between children with allergic SA not requiring omalizumab and those with allergic NSA, suggesting a low cost-effectiveness ratio, at least in the latter group. The global and direct costs of children with allergic SA were higher than those of children with non-allergic SA. This finding confirms that the presence of allergic comorbidities increases the costs of asthma management (11) and supports that allergy is associated with asthma severity. Our study had several limitations. Only a small number of children were included. However, we included children with well-defined doctor-confirmed SA, with and without omalizumab, reflecting the heterogenity of this population. In addition, our study was performed in a tertiary-care center. Thus the children with NSA may not be representative of community children. Our estimation was based on parental declarations, with a potential memory bias and a risk of misestimation of certain expenditures. We limited this risk by analyzing the medical records, which confirmed the parental claims. The best design would have been to obtain the data of children selected by a physician from the NHI. However, this approach is rarelly authorized in France. Moreover, the study covered a short period of time including winter and two months of spring, which may lead to underestimation of costs related to seasonal allergy treatments. In addition, the number of children under allergen immunotherapy was small ( 1 in the group of children with allergic SA vs. 4 children with allergic NSA $(\mathrm{p}=0.03)$ ).

In summary, this study is the first to precisely analyse the proportion of costs attributed to allergy in pediatric SA. As expected, allergy-related costs are mainly driven by omalizumab. However, for children with allergic SA who do not require omalizumab, the economic contribution of allergy to SA costs is relatively small, suggesting a low cost-effectiveness ratio.

\section{References}

1. Deschildre A, Marguet C, Salleron J, Pin I, Rittié J-L, Derelle J, et al. Add-on omalizumab in children with severe allergic asthma: a 1-year real life survey. Eur Respir J. 1 nov 2013;42(5):1224.

2. Just J, Gouvis-Echraghi R, Rouve S, Wanin S, Moreau D, Annesi-Maesano I. Two novel, severe asthma phenotypes identified during childhood using a clustering approach. Eur Respir J. juill 2012;40(1):55-60.

3. Deliu M, Belgrave D, Simpson A, Murray CS, Kerry G, Custovic A. Impact of rhinitis on asthma severity in school-age children. Allergy. nov 2014;69(11):1515-21.

4. Schwindt CD, Tjoa T, Floro JN, Mclaren C, Delfino RJ. Association of Atopy to Asthma Severity and Medication Use in Children. J Asthma. janv 2006;43(6):439-46.

5. Wang J, Visness C, Sampson H. Food allergen sensitization in inner-city children with asthma. J Allergy Clin Immunol. mai 2005;115(5):1076-80.

6. Friedlander JL, Sheehan WJ, Baxi SN, Kopel LS, Gaffin JM, Ozonoff A, et al. Food Allergy and Increased Asthma Morbidity in a School-Based Inner-City Asthma Study. J Allergy Clin Immunol Pract. 
sept 2013;1(5):479-84.

7. Pamuk G, Le Bourgeois M, Abou Taam R, de Blic J, Delacourt C, Lezmi G. The economic burden of severe asthma in children: a comprehensive study. J Asthma. 21 aout 2020; In Press .

8. Muraro A, Werfel T, Hoffmann-Sommergruber K, Roberts G, Beyer K, Bindslev-Jensen C, et al. EAACI Food Allergy and Anaphylaxis Guidelines: diagnosis and management of food allergy. Allergy. aout 2014;69(8):1008-25.

9. Seidman MD, Gurgel RK, Lin SY, Schwartz SR, Baroody FM, Bonner JR, et al. Clinical Practice Guideline: Allergic Rhinitis. Otolaryngol Neck Surg. fevr 2015;152(1_suppl):S1-43.

10. 2018 GINA Report, Global Strategy for Asthma Management and Prevention.

11. Schramm B, Ehlken B, Smala A, Quednau K, Berger K, Nowak D. Cost of illness of atopic asthma and seasonal allergic rhinitis in Germany: 1-yr retrospective study. Eur Respir J. janv 2003;21(1):116-22.

\section{Hosted file}

Tables.pdf available at https://authorea.com/users/363957/articles/484564-the-economicburden-of-allergy-in-pediatric-severe-asthma 